\title{
Concomitant phrenic nerve pacing and lobectomy in a patient with quadriplegia
}

\author{
Faouzi Alimi, MD, ${ }^{\mathrm{a}}$ Ciprian Pricopi, MD, ${ }^{\mathrm{a}}$ Capucine Morelot-Panzini, MD, ${ }^{\mathrm{b}}$ and \\ Françoise Le Pimpec-Barthes, MD, PhD, ${ }^{a}$ Paris, France
}

Patients with quadriplegia after cervical spinal cord injury requiring mechanical ventilation are at high risk for development of atelectasis and pneumonia. ${ }^{1}$ Those complications may lead to parenchymal destruction, chronic pulmonary infections with the development of multidrugresistant organisms, and an increase in cost of health care. To wean such patients from mechanical ventilation, reduce their incidence of pneumonia, and improve their quality of life, phrenic nerve pacing may be proposed in carefully selected cases. Here we report the case of a patient for whom phrenic nerve pacing was indicated but delayed because of recurrent pneumonias. We finally decided to combine a lobectomy, indicated because of lobar destruction from chronic suppuration, with phrenic nerve pacing. We were aware of potential septic risks, but we wanted to avoid separate highly risky procedures.

\section{CLINICAL SUMMARY}

A 31-year-old man with $\mathrm{C} 1$ quadriplegia resulting from a gun injury 43 months earlier was dependent on mechanical ventilation and had recurrent pulmonary infections. After complete neuromuscular investigation, phrenic nerve pacing was proposed to wean the patient from the ventilator and to improve his respiratory function. The proposed surgical procedure was controversial, however, because of persistent pulmonary infection with multidrug-resistant bacteria (Pseudomonas aeruginosa) and of the necessity of frequent fiberoptic bronchoscopies. A chest computed tomographic scan was done and showed complete destruction of the left lower lobe with bronchiectasis (Figure 1). We finally decided to remove the destroyed lobe because of the uncontrolled septic condition with permanent atelectasis and for simultaneous implantation

From the Department of Thoracic Surgery, ${ }^{\text {a }}$ Georges Pompidou European Hospital, Paris-Descartes University, Paris, France; and the Respiratory and Intensive Medicine Unit, ${ }^{\mathrm{b}}$ Pitié Salpêtrière Hospital, Paris, France.

Disclosures: Authors have nothing to disclose with regard to commercial support.

Received for publication June 23, 2013; revisions received Dec 25, 2013; accepted for publication Jan 31, 2014; available ahead of print March 4, 2014.

Address for reprints: Françoise Le Pimpec-Barthes, MD, PhD, Department of Thoracic Surgery, Georges Pompidou European Hospital, 20 Rue Leblanc 75015, Paris, France (E-mail: francoise.lepimpec-barthes@egp.aphp.fr).

J Thorac Cardiovasc Surg 2014;147:e70-1

$0022-5223 / \$ 36.00$

Copyright (c) 2014 by The American Association for Thoracic Surgery

http://dx.doi.org/10.1016/j.jtcvs.2014.01.050

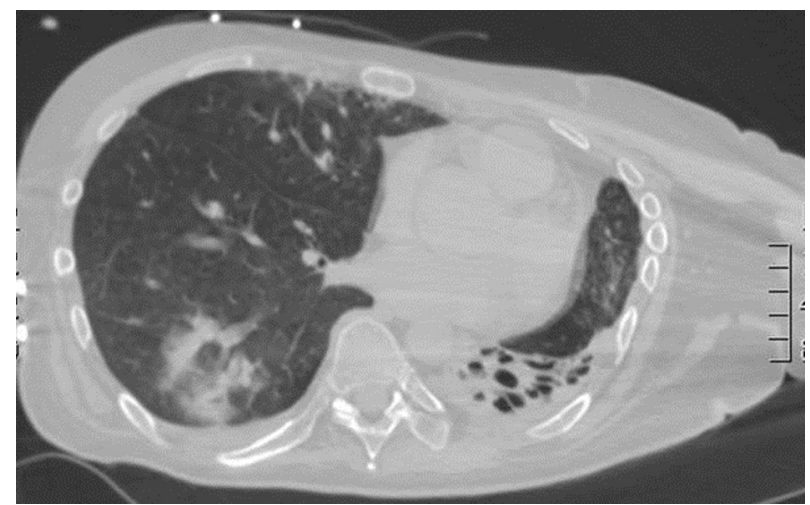

FIGURE 1. Chest computed tomography showing the complete destruction of the left lower lobe with bronchiectasis and retraction of the left hemithorax as sequelae of a chronic infection.

of a phrenic pacing unit. A combination of ceftazidime and imipenem was used during the perioperative course. Technically, we first performed a left posterolateral thoracotomy to do the left lower lobectomy. Then the quadripolar electrodes were placed around the left phrenic nerve (Figure 2). On the right side, the procedure was performed thoracoscopically with a small parasternal incision, as previously described. ${ }^{2}$ Intraoperative testing showed homogeneous stimulation thresholds for the 4 components of the quadripolar electrodes. Visible

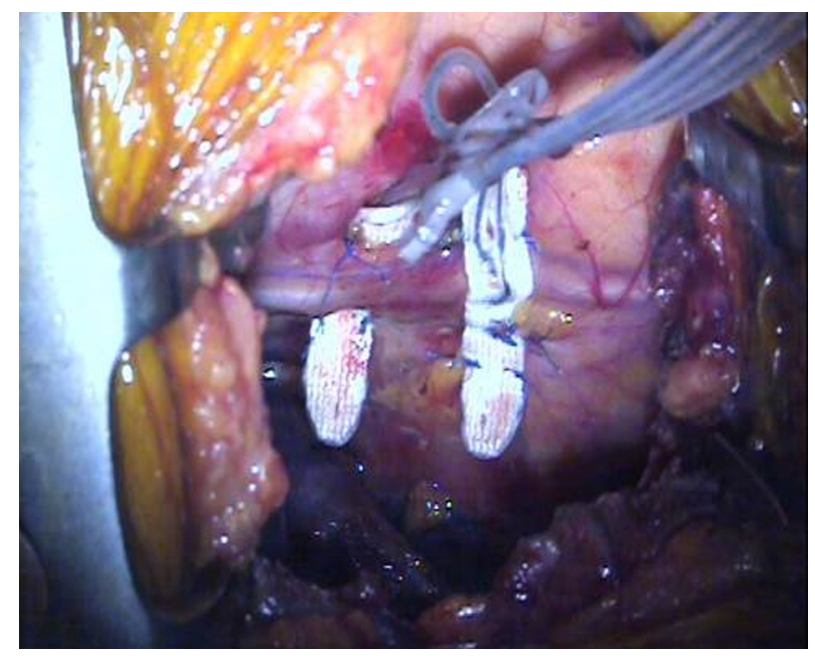

FIGURE 2. Quadripolar electrodes placed around, under, and above the phrenic nerve. 
diaphragmatic contractions were obtained on both sides. The postoperative course was uneventful. Diaphragm reconditioning was started 3 weeks after the operation until full weaning from the ventilator with effective spontaneous ventilation was accomplished. At that time, the tidal volume was between 400 and $500 \mathrm{~mL}$. The patient's quality of life improved, he was discharged without ventilatory support, and he needed less tracheal suctioning. No recurrent pulmonary infection has been reported since that time.

\section{DISCUSSION}

This case illustrates the feasibility of combined surgical procedures in a patient with major comorbidities. To our knowledge, this is a unique case of concomitant phrenic nerve pacing and lobectomy. The 2 main indications for phrenic nerve pacing are improvement in quality of life and reduction of the occurrence of respiratory infection by discontinuing mechanical ventilation. It is directly linked to the cessation of positive pressure ventilation and the achievement of more physiologic breathing by bilateral phrenic nerve stimulation. In patients who have been weaned, the decrease in bronchial secretions requires less tracheal suctioning and the incidence of respiratory infections is lower. ${ }^{2,3}$ It also reduces the costs of health care. $^{2}$

For our patient, the decision for combined surgery was made to remove the infected area before implantation of the intrathoracic device, avoiding separate surgical procedures that might well be more difficult the second time. The main postoperative risks were infection around the device and pneumonia from established multidrugresistant bacteria. ${ }^{1}$ In our institution, we have performed 36 phrenic nerve pacing procedures in patients with quadriplegia or with congenital neurologic disorders, and a report of the first 20 cases has already been published. ${ }^{2}$ The device was implanted by a video-assisted thoracoscopic surgical procedure in all cases but never in association with lobectomy except in this case. As we gained experience with the perioperative treatment of patients with quadriplegia, it seemed feasible to extend our approach to include concomitant resectional surgery. Thoracic surgery in patients with quadriplegia is not common, because there are few patients and the indications are unusual. ${ }^{3,4}$ The main risk during the surgical procedure in such patients is the neurologic dysautonomia phenomenon, with cardiac abnormalities and major alterations in the body's homeostasis. ${ }^{5}$ The safety of the pulmonary resection was evaluated by echocardiography and computed tomography but not by pulmonary function tests, which are impossible to perform in patients on a ventilator. No change in respiratory function was anticipated, because the proposed resected lobe was already totally destroyed. We only could find 4 published cases of lobectomy in patients with quadriplegia, and all those patients had spontaneous respiration and were free from any ventilator assistance. ${ }^{3,4}$ In the first case, reported by Rocco and colleagues, ${ }^{3}$ the clinical presentation of $\mathrm{C} 3$ level quadriplegia raised the question of a severe diaphragmatic malfunction, suggested by the need for postoperative rehabilitation and reconditioning of the accessory muscles of respiration. An associated phrenic nerve pacing might possibly be beneficial to such a patient. Infectious lung complications in patients with quadriplegia are the leading cause of in-hospital morbidity and mortality and are directly related to long-term tracheotomy and mechanical ventilation. Another complicating factor is the diaphragmatic eventration secondary to the absence of nerve stimulation, with resultant compression of the base of the lung.

\section{CONCLUSIONS}

We present a case of concomitant lobectomy and placement of a phrenic nerve pacing device in a patient with quadriplegia. This combined procedure allowed weaning from mechanical ventilation and control of recurrent infection by removing a destroyed, infected lobe.

\section{References}

1. McKinley WO, Jackson AB, Cardenas DD, DeVivo MJ. Long-term medica complications after traumatic spinal cord injury: a regional model systems analysis. Arch Phys Med Rehabil. 1999;80:1402-10.

2. Le Pimpec-Barthes F, Gonzalez-Bermejo J, Hubsch JP, Duguet A, MorélotPanzini C, Riquet M, et al. Intrathoracic phrenic pacing: a 10-year experience in France. J Thorac Cardiovasc Surg. 2011;142:378-83.

3. Rocco G, Della Pona C, Massera F, Robustellini M, Rossi G, Rizzi A Lobectomy for destroyed lung in quadriplegic patients. Ann Thorac Surg. 2000 69:1002-5

4. Noly PE, Arame A, Riquet M, Le Pimpec-Barthes F. The reliability of lung function tests in a quadriplegic patient. J Thorac Cardiovasc Surg. 2012;144: e116-7

5. Houtman S, Oeseburg B, Hughson RL, Hopman MT. Sympathetic nervous system activity and cardiovascular homeostasis during head-up tilt in patients with spinal cord injuries. Clin Auton Res. 2000;10:207-12. 